\title{
Uniformly dimerized C60 film prepared by deposition under in situ photoirradiation
}

\author{
H. Tanimoto, ${ }^{1, a)}$ K. Yamada, ${ }^{1}$ H. Mizubayashi, ${ }^{1}$ Y. Matsumoto, ${ }^{2}$ H. Naramaoto, ${ }^{2}$ and \\ S. Sakai ${ }^{2}$ \\ ${ }^{1}$ Graduate School of Pure and Applied Sciences, University of Tsukuba, Tsukuba, Ibaraki 305-8573, Japan \\ ${ }^{2}$ Advanced Science Research Center, Japan Atomic Energy Agency (JAEA), 2-4 Shirakata Shirane, \\ Tokai-mura, Naka-gun, Ibaraki 319-1195, Japan
}

(Received 27 August 2008; accepted 30 September 2008; published online 17 October 2008)

\begin{abstract}
C60 films with thicknesses of 100-480 nm were deposited on Si reed substrates under in situ photoirradiation. In anelasticity measurements, no internal friction peaks associated with rotational motions of the C60 molecules were observed, and Young's modulus was 1.5 times larger than that of a pristine C60 material. X-ray diffraction patterns suggested that the face-centered cubic lattice was contracted by about 3\% and locally distorted from the pristine C60 material. Raman spectra very similar to those reported for dimerized $\mathrm{C} 60$ were also obtained. These characteristics recovered to those of the pristine $\mathrm{C} 60$ materials after annealing the $\mathrm{C} 60 \mathrm{films}$ at $523 \mathrm{~K}$. These results indicate uniform dimerization in C60 films deposited under in situ photoirradiation. () 2008 American Institute of Physics. [DOI: 10.1063/1.3003866]
\end{abstract}

Covalent bonding between $\mathrm{C} 60$ molecules (i.e., polymerization) can be generated in a pristine face-centered cubic (fcc) C60 material by several methods, including photoirradiation, ${ }^{1}$ high-energy particle irradiation, ${ }^{2,3}$ or highpressure, high-temperature (HPHT) treatment. ${ }^{4,5}$ Polymerized C60 materials are regarded as a new type of carbon material in which the $s p^{2}$ and $s p^{3}$ bonding states coexist. ${ }^{6}$ Photoirradiation is an easy way to prepare polymerized C60 films and is applicable for device fabrication. The penetration depth of ultraviolet to visible light in C60 materials, however, is limited to the order of $100 \mathrm{~nm}$.

Recoverable but time-dependent elastic behavior is referred to as anelasticity. ${ }^{7}$ The dynamic motion of atoms and molecules or phase transition in solids often induces anelastic relaxation similar to dielectric or magnetic relaxation, with the internal friction giving a measure of the fractional energy loss per cycle in periodic deformation due to anelasticity. Two internal friction peaks associated with the rotational motion of C60 molecules have been reported for C60 materials at around $260 \mathrm{~K}$ and below $260 \mathrm{~K}$ (referred to hereafter as $P 2$ and $P 1$, respectively). ${ }^{8-11} P 2$ is attributed to a structural phase transition from the fcc phase to a simple cubic phase as a result of orientational ordering about the rotation axis at around $260 \mathrm{~K},{ }^{8,9}$ whereas $P 1$ is attributed to thermal jumping between two energetically quasiequivalent rotational configurations of adjacent $\mathrm{C} 60$ molecules, in relation to their activation parameters. ${ }^{12-14}$ When covalent bonds are formed between $\mathrm{C} 60$ molecules, $P 1$ and $P 2$ are expected to disappear through suppression of these rotational motions, whereas the modulus is increased through strengthening of the intermolecular bonding. In the present study, C60 deposition under in situ photoirradiation was applied to prepare photopolymerized C60 films with thicknesses up to $480 \mathrm{~nm}$, and the morphology of these films was investigated in terms of their anelastic property, as well as through x-ray diffrac-

\footnotetext{
a) Author to whom correspondence should be addressed. Electronic mail: tanimoto@ims.tsukuba.ac.jp. Tel.: +81-298-53-5360. FAX: +81-298-534490.
}

tion (XRD) and Raman spectroscopy measurements.

The C60 deposition was carried out on a Si reed substrate (reed dimensions: $15 \times 3 \times \sim 0.1 \mathrm{~mm}^{3}$ ) (Ref. 15) at $348 \mathrm{~K}$ with a Knudsen cell in ultrahigh vacuum (base pressure below $10^{-6} \mathrm{~Pa}$ ). The deposition rate was about 0.06 $\mathrm{nm} / \mathrm{min}$. Blue light from high-power light-emitting diodes (Lumileds Luxeon K2, peak wavelength: $470 \mathrm{~nm}$ ) was guided to the vacuum chamber through a viewing port so that the light intensity at the substrate was about $0.25 \mathrm{~W} / \mathrm{cm}^{2}$. The photoabsorption observed for pristine $\mathrm{C} 60$ film at around $2.7 \mathrm{eV}(458 \mathrm{~nm})$ is assigned to the intermolecular charge-transfer state. ${ }^{16}$ For the in situ photoirradiation during C60 deposition, the substrate was tilted to $45^{\circ}$ with respect to both the direction to the Knudsen cell and the incident light. The anelasticity was measured by a composite reed vibration technique. ${ }^{15,17}$ The dynamic Young's modulus of the C60 film $\left(E_{\mathrm{C} 60}\right)$ was estimated from the change in the reed's resonant frequency as a result of the C60 deposition, where Poisson's ratio values of 0.306 reported for a C60 fcc single crystal ${ }^{18}$ and of 0.42 for $\mathrm{Si}$ were used. The Raman spectrum was measured with a micro-Raman spectrometer (Nano Finder, Tokyo Instruments) under a backscattering configuration. A 488-nm Ar-ion laser beam with a spot size of $0.5 \mathrm{~mm} \phi$ and an intensity of $\sim 0.05 \mathrm{~mW}$ was used for irradiation, and no spectral changes were found during the measurements. The XRD spectrum was recorded by using a diffractometer (Philips X'pert) with $\mathrm{Cu} K \alpha$ radiation. An evacuation chamber was used to reduce the background scattering, and the remaining background in the raw spectrum was subtracted by assuming a polynomial function.

Figure 1(a) shows the internal friction spectrum observed for a 480-nm-thick C60 film deposited on the Si reed substrate under in situ photoirradiation and then subjected to annealing at $523 \mathrm{~K}$ for $48 \mathrm{~h}$ in vacuum $\left(<4 \times 10^{-5} \mathrm{~Pa}\right)$. In Fig. 1(a), the increase in internal friction observed above 200 $\mathrm{K}$ for the substrate alone was due to the thermoelastic damping of $\mathrm{Si}$. The internal friction from the $\mathrm{C} 60$ film $\left(\Delta Q^{-1}\right)$ is depicted in Fig. 1(b) after subtraction of the Si reed component. As shown in Fig. 1(b), the $P 1$ and $P 2$ peaks were not 


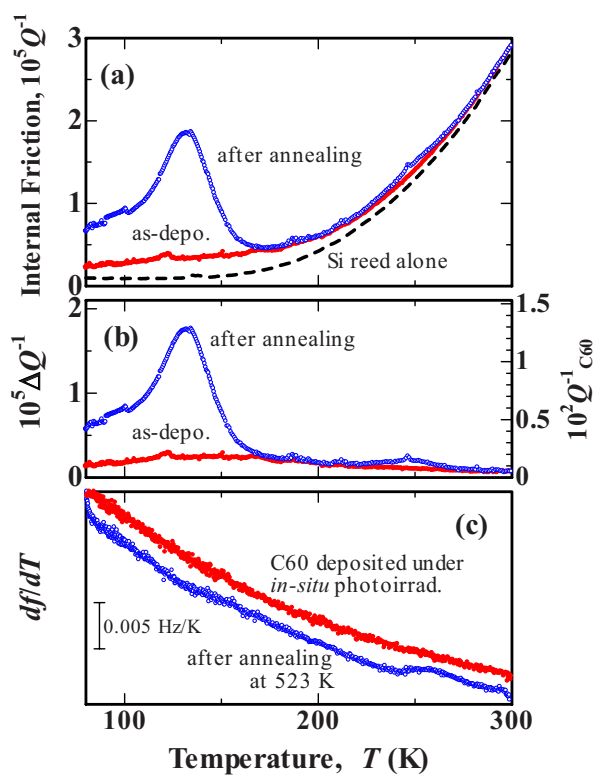

FIG. 1. (Color online) (a) Internal friction spectrum observed for a composite reed of C60 film (480 nm thick) deposited on a Si substrate under in situ photoirradiation (red) and that for the same specimen after annealing at 523 $\mathrm{K}$ (blue). The dashed line represents the spectrum for the Si reed substrate alone. (b) Internal friction spectra for the C60 film $\left(\Delta Q^{-1}\right)$ estimated by subtraction of the Si reed component from the spectra in (a), where $\Delta Q^{-1}$ was converted to the internal friction of the $\mathrm{C} 60$ film $\left(Q_{C 60}^{-1}\right)$ on the righthand axis. (c) Temperature derivative curves of the resonant frequency observed for the composite reed with the $\mathrm{C} 60$ film deposited on the $\mathrm{Si}$ substrate.

immediately observed for the C60 film deposited under in situ photoirradiation (hereafter referred to as in situ irrad. C60 film) but did appear after the annealing. Figure 1(c) shows the temperature derivative of the resonant frequency (proportional to the square root of Young's modulus) observed for the in situ irrad. C60 film and the film after annealing. The curve of the derivative for the in situ irrad. C60 film showed a monotonic decrease with increasing temperature. After annealing, a steplike increase at around $250 \mathrm{~K}$ and a dip at around $130 \mathrm{~K}$ appeared; these features correspond to $P 2$ and $P 1$, respectively. In the thermodynamic measurement of the C60 subjected to HPHT treatment, the small enthalpy of transition observed at $260 \mathrm{~K}$ could be explained by the residual C60 monomers. ${ }^{19}$ In the present experiment, no anomalous change in Young's modulus of the in situ irrad. C60 film was detected near the temperature corresponding to $P 2$. These observations suggest that the rotational motions of the C60 molecules were completely suppressed in the in situ irrad. C60 film but revived after the annealing at $523 \mathrm{~K}$. It has been reported that C60 dimers induced by photoirradiation are dissolved by heating to above $473 \mathrm{~K}^{20,21}$ Similar results to those shown in Figs. 1(a) and 1(b) were also observed for in situ irrad. C60 films with thicknesses of 95 and $150 \mathrm{~nm}$.

Table I lists the $E_{\mathrm{C} 60}$ values estimated for the in situ irrad. C60 films, where the estimation accounted for the lattice contraction found from the XRD measurements (see below). The $E_{\mathrm{C} 60}$ estimated for the in situ irrad. C60 films was about 1.5 times larger than that for pristine C60 film or the value of 12-16 GPa reported for polycrystalline C60. ${ }^{8,22}$ After annealing at $523 \mathrm{~K}$, the $E_{\mathrm{C} 60}$ value decreased to that of pristine C60. It has been reported that one- or twodimensionally polymerized HPHT C60 materials exhibit a
TABLE I. Dynamic Young's moduli of C60 films $\left(E_{\mathrm{C} 60}\right)$ deposited under in situ photoirradiation and after annealing at $523 \mathrm{~K}$. The value observed for pristine C60 film deposited without photoirradiation is also listed.

\begin{tabular}{cccc}
\hline \hline $\begin{array}{c}\text { C60 thickness } \\
(\mathrm{nm})\end{array}$ & $\begin{array}{c}E_{\mathrm{C} 60}(\mathrm{GPa}) \\
\text { In situ } \text { photoirrad. }\end{array}$ & $\begin{array}{c}\text { After 523 K } \\
\text { annealing }\end{array}$ & $\begin{array}{c}\text { Without } \\
\text { photoirrad. }\end{array}$ \\
\hline 95 & 21.6 & 17.7 & $\ldots$ \\
150 & 25.7 & 22.0 & $\ldots$ \\
480 & 24.3 & 17.5 & $\ldots$ \\
165 & $\cdots$ & $\cdots$ & 16.5 \\
\hline \hline
\end{tabular}

Young's modulus of about 25 or $45 \mathrm{MPa}$, respectively, and both recover to the fcc C60 material by annealing above 600 $\mathrm{K}{ }^{23}$ The Young's modulus and recovery temperature observed here suggest that long polymerized chains were not formed in the in situ irrad. C60 films.

Figure 2 shows the XRD spectra obtained for the 480nm-thick in situ irrad. C60 film and the same film after annealing, together with the XRD spectrum for pristine C60 film. The XRD pattern observed for the pristine C60 film can be explained by its fcc structure with a lattice constant of $1.417 \mathrm{~nm} .{ }^{4}$ For the in situ irrad. C60 film, the (111) and (220) reflections exhibited a position shift to a higher angle and peak broadening, as compared with the pristine C60 film. From the (111) and (220) reflections, the lattice parameter was estimated to be about $1.37 \mathrm{~nm}$, suggesting lattice contraction by about $3.3 \%$ from the pristine fcc lattice. The reflection at around $21.7^{\circ}$ can be identified as the (311) reflection of the contracted fcc lattice. The reflection at around $14^{\circ}$, on the other hand, cannot be expected from the normal reflections of both the pristine $\mathrm{C} 60 \mathrm{fcc}$ lattice and the contracted one, but the peak position coincides with the forbidden (210) reflection of the pristine lattice. In addition to the broadened reflections, the reflection at around $14^{\circ}$ suggests that the in situ irrad. C60 film had a locally distorted fcc structure. The reflections observed after annealing at $523 \mathrm{~K}$ were explained well by the pristine $\mathrm{C} 60 \mathrm{fcc}$ structure and became sharper, suggesting that the contracted, distorted fcc structure nearly recovered to the pristine one. The reflection at around $14^{\circ}$, however, remained, and the other reflections were slightly broader than those of the pristine C60 film. These results indicate that a portion of the lattice distortions remained even after the polymerization dissolved. The fcc

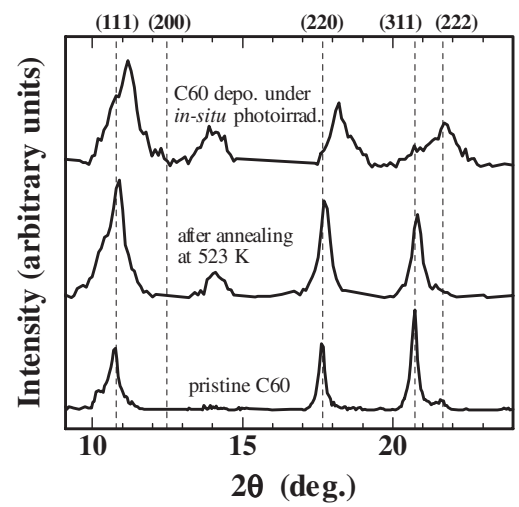

FIG. 2. XRD spectra obtained for a C60 film (480 nm thick) deposited under in situ photoirradiation and the same film after annealing at $523 \mathrm{~K}$. The spectrum obtained for pristine C60 film (210 nm thick) is also shown. The vertical dashed lines indicate the peak positions for the C60 fcc structure with a lattice parameter of $1.417 \mathrm{~nm}$. 


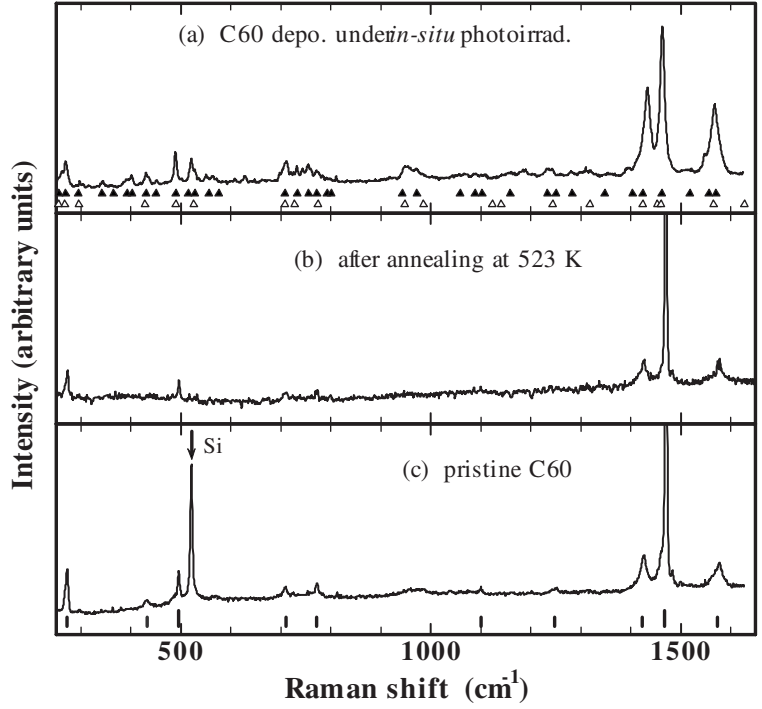

FIG. 3. Raman spectra obtained for (a) a C60 film (480 nm thick) deposited under in situ photoirradiation and (b) the same film after annealing at $523 \mathrm{~K}$. In (a), the filled and open triangles indicate the peak positions reported for a dimerized HTHP C60 specimen ${ }^{27}$ and a photopolymerized C60 film, ${ }^{28}$ respectively. The spectrum obtained for a pristine C60 film (165 nm thick) deposited without photoirradiation is shown in (c), where the peak at $521 \mathrm{~cm}^{-1}$ was due to the $\mathrm{Si}$ substrate and the vertical bars indicate the peak positions reported for the pristine fcc C60 material.

structure contracted by $3.7 \%$ and its recovery after annealing at $543 \mathrm{~K}$ has been reported for an HPHT-treated C60 material $(5 \mathrm{GPa}$ at $573 \mathrm{~K}),{ }^{4}$ and similar lattice changes have been reported for an HPHT-treated C60 crystal (2 GPa at 700 $\mathrm{K}){ }^{24}$ The small peak shifts from the perfect fcc position by dimerization are attributed to the distorted fcc structure observed for C60 subjected to HPHT treatment at $1.5 \mathrm{GPa}$ and $423 \mathrm{~K}^{25}$

Figures 3(a)-3(c) show the Raman spectra obtained for a 480-nm-thick in situ irrad. C60 film, the same film after annealing at $523 \mathrm{~K}$ for $48 \mathrm{~h}$, and a pristine C60 film, respectively. The large peak observed at around $1468 \mathrm{~cm}^{-1}$ for the pristine C60 film [Fig. 3(c)] was identified as the $A_{g}(2)$ peak, which is attributed to the pentagon pinching mode of a C60 molecule. It has been reported that the $A_{g}(2)$ peak is quenched and other peaks are observed below the $A_{g}(2)$ peak because of $\mathrm{C} 60$ dimer formation resulting from the $2+2$ cycloaddition reaction. ${ }^{1,26}$ Instead of the $A_{g}(2)$ peak, a large peak at around $1462 \mathrm{~cm}^{-1}$ and small peaks below $1400 \mathrm{~cm}^{-1}$ were observed for the in situ irrad. C60 film [Fig. 3(a)]. These peaks are well explained in terms of those reported for an HPHT dimerized C60 crystal (filled triangles) ${ }^{27}$ or those reported for a photodimerized C60 film (open triangles). ${ }^{28}$ After annealing at $523 \mathrm{~K}$, the $A_{g}(2)$ peak revived and the $\mathrm{C} 60$ dimer-related peaks disappeared. These observations indicate $\mathrm{C} 60$ dimer formation in the in situ irrad. C60 film and then dissolution into C60 monomers after annealing. Similar Raman spectra were also observed for the 95- and 150-nm-thick in situ irrad. C60 films.

All the present results demonstrate that uniformly dimerized C60 films with a thickness greater than the light penetration depth can be prepared by deposition under in situ photoirradiation. We propose that several C60 dimers aligned in a $\langle 110\rangle$ direction constitute a fundamental structural unit, and that the contracted, locally distorted fcc lattice is formed by an aggregate of variants with different orientations. The reflection observed at around $14^{\circ}$ in the XRD pattern might be attributed to local fcc lattice distortions induced by variant formation. Since it is reported that the two-dimensional hexagonal C60 photopolymer exhibits a semiconducting property, ${ }^{29}$ the electrical conductivity of the present C60 films is of great interest. Further investigations of the electrical property as well as the texture and the formation process are in progress.

${ }^{1}$ A. M. Rao, P. Zhou, K.-A. Wang, G. T. Hager, J. M. Holden, Y. Yang, W. T. Lee, X.-X. Bi, P. C. Eklund, D. S. Cornett, M. A. Duncan, and I. J. Amster, Science 259, 955 (1993).

${ }^{2}$ L. Palmetshofer and J. Kastner, Nucl. Instrum. Methods Phys. Res. B 96, 343 (1995).

${ }^{3}$ T. Hara, J. Onoe, H. Tanaka, Y. Li, and K. Takeuchi, Jpn. J. Appl. Phys., Part 1 39, 1872 (2000)

${ }^{4}$ Y. Iwasa, T. Arima, R. M. Fleming, T. Siegrist, O. Zhou, R. C. Haddon, L. J. Rothberg, K. B. Lyons, H. L. Carter, Jr., A. F. Hebard, R. Tycko, G. Dabbagh, J. J. Krajewski, G. A. Thomas, and T. Yagi, Science 264, 1570 (1994).

${ }^{5}$ M. Núñez-Regueiro, L. Marques, L.-J. Hodeau, O. Béthoux, and M. Perroux, Phys. Rev. Lett. 74, 278 (1995).

${ }^{6}$ S. Okada, S. Saito, and A. Oshiyama, Phys. Rev. Lett. 83, 1986 (1999).

${ }^{7}$ A. S. Nowick and B. S. Berry, Anelastic Relaxation in Crystalline Solids (Academic, New York, 1972).

${ }^{8}$ X. D. Shi, A. R. Kortan, J. M. Williams, A. M. Kini, B. M. Savall, and P. M. Chaikin, Phys. Rev. Lett. 68, 827 (1992).

${ }^{9}$ S. Hoen, N. G. Chopra, X.-D. Xiang, R. Mostovoy, J. Hou, W. A. Vareka, and A. Zettel, Phys. Rev. B 46, 12737 (1992).

${ }^{10}$ F. Yan, Y. N. Wang, and M. Gu, Phys. Rev. B 55, R4918 (1997).

${ }^{11}$ H. Tanimoto, H. Mizubayashi, S. Sakai, K. Narumi, and H. Naramoto, Mater. Sci. Eng., A 442, 319 (2006).

${ }^{12}$ R. Tycko, G. Dabbagh, R. M. Fleming, R. C. Hadden, A. V. Makhija, and S. M. Zahurak, Phys. Rev. Lett. 67, 1886 (1991).

${ }^{13}$ W. Schranz, A. Fuith, P. Dolinar, H. Warhanek, M. Haluska, and H. Kuzmany, Phys. Rev. Lett. 71, 1561 (1993).

${ }^{14}$ W. I. F. David, R. M. Ibberson, T. J. S. Dennis, J. P. Hare, and K. Prassides, Europhys. Lett. 18, 219 (1992).

${ }^{15}$ H. Mizubayashi, Y. Yoshihara, and S. Okuda, Phys. Status Solidi A 129, 475 (1992).

${ }^{16}$ S. Kazaoui, R. Ross, and N. Minami, Phys. Rev. B 52, R11665 (1995).

${ }^{17}$ B. S. Berry and A. C. Pritchet, J. Phys. (Paris) 42, C5-1111 (1981).

${ }^{18}$ N. P. Kobelev, R. K. Nikolaev, Y. M. Soifer, and S. S. Khasanov, Chem. Phys. Lett. 276, 263 (1997).

${ }^{19}$ B. V. Lebedev, A. V. Markin, V. A. Davydov, L. S. Kashevarova, and A V. Rakhmanina, Thermochim. Acta 399, 99 (2003).

${ }^{20}$ Y. Wang, J. M. Holden, Z. H. Dong, X. X. Bi, and P. C. Eklund, Chem. Phys. Lett. 211, 341 (1993).

${ }^{21}$ P. C.. Eklund, A. M. Rao, P. Zhou, Y. Wang, and J. M. Holden, Thin Solid Films 257, 185 (1995).

${ }^{22}$ H. Coufal, K. Meyer, R. K. Grygier, M. de Vries, D. Jenrich, and P. Hess, Appl. Phys. A: Solids Surf. 59, 83 (1994).

${ }^{23}$ Y. M. Soifer, N. P. Kobelev, and V. M. Levin, J. Alloys Compd. 310, 292 (2000).

${ }^{24}$ I. Bashkin, V. Rashchupkin, A. Gurov, A. Moravsky, O. Rybchenko, N Kobelev, Y. Soifer, and E. Ponyatovsky, J. Phys.: Condens. Matter 6, 7491 (1994).

${ }^{25}$ V. A. Davydov, L. S. Kashevarova, A. V. Rakhmanina, V. Agafonov, H. Allouchi, R. Céolin, A. V. Dzyabchenko, V. M. Senyavin, H. Szwarc, T. Tanaka, and K. Komatsu, J. Phys. Chem. B 103, 1800 (1999).

${ }^{26}$ G. B. Adams, J. B. Page, O. F. Sankey, and M. O'Keeffe, Phys. Rev. B 50, 17471 (1994)

${ }^{27}$ V. A. Davydov, L. S. Kashevarova, A. V. Rakhmanina, R. Céolin, H. Szwarc, H. Allouchi, and V. Agafonov, Phys. Rev. B 61, 11936 (2000).

${ }^{28}$ A. M. Rao, P. C. Eklund, U. D. Venkateswaran, J. Tucker, M. A. Duncan, G. M. Bendele, P. W. Stephens, J.-L. Hodeau, L. Marques, M. NúñezRegueiro, I. O. Bashkin, E. G. Ponyatovsky, and A. P. Morovsky, Appl. Phys. A: Mater. Sci. Process. 64, 231 (1997).

${ }^{29}$ J. Onoe, T. Nakayama, M. Aono, and T. Hara, J. Phys. Chem. Solids 65 , 343 (2004). 